\title{
Formaldehyde in Alcoholic Beverages: Large Chemical Survey Using Purpald Screening Followed by Chromotropic Acid Spectrophotometry with Multivariate Curve Resolution
}

\author{
Julien A. Jendral, ${ }^{1}$ Yulia B. Monakhova, ${ }^{1,2}$ and Dirk W. Lachenmeier ${ }^{1}$ \\ ${ }^{1}$ Chemisches und Veterinäruntersuchungsamt (CVUA) Karlsruhe, Weissenburger Straße 3, 76187 Karlsruhe, Germany \\ ${ }^{2}$ Department of Chemistry, Saratov State University, Astrakhanskaya Street 83, Saratov 410012, Russia \\ Correspondence should be addressed to Dirk W. Lachenmeier, lachenmeier@web.de
}

Received 11 January 2011; Revised 8 March 2011; Accepted 30 March 2011

Academic Editor: Jan Åke Jönsson

Copyright () 2011 Julien A. Jendral et al. This is an open access article distributed under the Creative Commons Attribution License, which permits unrestricted use, distribution, and reproduction in any medium, provided the original work is properly cited.

\begin{abstract}
A strategy for analyzing formaldehyde in beer, wine, spirits, and unrecorded alcohol was developed, and 508 samples from worldwide origin were analyzed. In the first step, samples are qualitatively screened using a simple colorimetric test with the purpald reagent, which is extremely sensitive for formaldehyde (detection limit $0.1 \mathrm{mg} / \mathrm{L}$ ). 210 samples (41\%) gave a positive purpald reaction. In the second step, formaldehyde in positive samples is confirmed by quantitative spectrophotometry of the chromotropic acid-formaldehyde derivative combined with Multivariate Curve Resolution-Alternating Least Squares (MCR-ALS). Calculation of UV-VIS and ${ }^{13} \mathrm{C}$ NMR spectra confirmed the monocationic dibenzoxanthylium structure as the product of the reaction and disproved the widely cited para,para-quinoidal structure. Method validation for the spectrophotometric procedure showed a detection limit of $0.09 \mathrm{mg} / \mathrm{L}$ and a precision of $4.2-8.2 \%$ CV. In total, 132 samples (26\%) contained formaldehyde with an average of $0.27 \mathrm{mg} / \mathrm{L}$ (range $0-14.4 \mathrm{mg} / \mathrm{L}$ ). The highest incidence occurred in tequila $(83 \%)$, Asian spirits (59\%), grape marc $(54 \%)$, and brandy (50\%). Our survey showed that only 9 samples $(1.8 \%)$ had formaldehyde levels above the WHO IPCS tolerable concentration of $2.6 \mathrm{mg} / \mathrm{L}$.
\end{abstract}

\section{Introduction}

The International Agency for Research on Cancer (IARC) has upgraded the cancer classification of formaldehyde in 2006 to now being clearly "carcinogenic to humans" (group 1) [1]. More recently, formaldehyde has been implicated by the IARC as a causative agent of leukemia as well as nasopharyngeal cancer in humans [2]. The US EPA provides a reference dose for chronic oral exposure (RfD) of $0.2 \mathrm{mg} / \mathrm{kg}$ bodyweight/day [3]. The WHO IPCS [4] has established a tolerable concentration (TC) of $2.6 \mathrm{mg} / \mathrm{L}$ in ingested products based on animal experiments [5]. Systematic data are currently lacking regarding the formaldehyde content of alcoholic beverages or indeed of most food in general. Feron et al. [6] estimated that the formaldehyde intake by food may range between 1.5 and $14 \mathrm{mg} /$ person/day, which could, therefore, exceed the RfD in a worst case scenario.
As we had previously conducted in-depth research into acetaldehyde content of alcoholic beverages $[9,10]$, we were recently asked if we had similar data on formaldehyde and if this compound may pose a risk to consumers in addition to the risk of ethanol [11]. We had no such data, because formaldehyde cannot be analyzed along with the other volatiles (e.g., acetaldehyde and methanol) during a typical gas chromatographic reference method [12]. For this reason, a separate assay has to be developed. It quickly became clear that instrumental techniques such as GC [1320], HPLC [21-30], or flow-injection fluorimetric analysis [31-33], which require extensive sample preparation and derivatization steps, in addition to having costly and complicated instrumental requirements, would not be feasible for the economic and time-efficient survey of a large number of samples. In contrast, the commonly applied AOAC reference method 931.08 [34], based on the chromotropic 


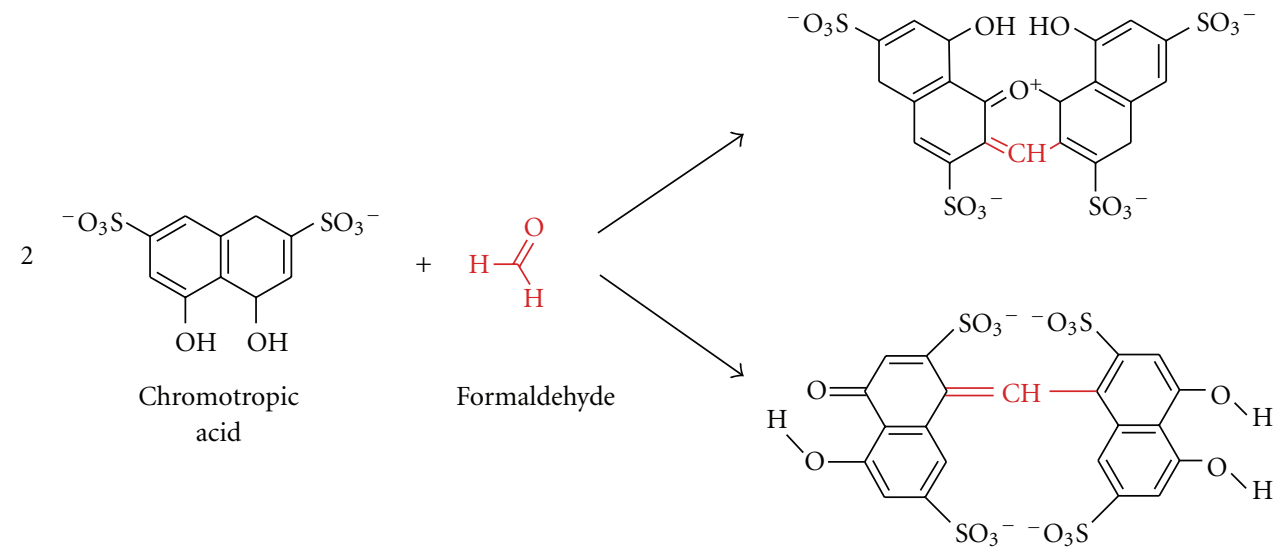

FIGURE 1: Hypothetical reaction products of the chromotropic acid-formaldehyde reaction [7]. The monocationic dibenzoxanthylium structure (1) is the more likely product (see text).

acid reaction first described by Eegriwe [35], appeared to be applicable (Figure 1). However, it is a comparatively timeconsuming method, which meant that the sample throughput would not have been large (our aim was to analyze at least 100 samples to provide a valid exposure assessment for consumers). Therefore, we had the idea to preselect samples for the AOAC procedure by first using a rapid colorimetric screening test for formaldehyde. A number of these tests are available for screening of aldehydes (e.g., Fehling's, Tollen's and Schiff's reagents, see summary by Brandl [36]), but these classical tests suffer from their low specificity. However, as late as 1970, a new test using purpald reagent (4-amino-3hydrazino-5-mercapto-1,2,4-triazole, CAS\# 1750-12-5) was developed, which is remarkably sensitive and specific for aldehydes $[8,37,38]$. The purpald reaction is based on a condensation of formaldehyde with the reagent to form an aminal, which then reacts under aeration (facilitated by vigorously shaking of the solution) to form a purple coloured oxidation product (Figure 2). The reaction is sensitive for aldehydes, as ketones are oxidized to an uncoloured product $[8,37]$.

Conveniently, the reagents needed for the purpald as well as the chromotropic acid determination are available in ready-to-use test kits (intended for water or disinfectant analysis), and these appear to be usable for testing of alcoholic beverages as well. The major aim of this paper is to evaluate this two-step strategy to provide a survey of formaldehyde in alcoholic beverages. Furthermore, we provide some insight into the structure of the formaldehydechromotropic acid chromogen and apply multivariate curve deconvolution techniques to improve the spectrophotometric assay.

\section{Experimental Section}

2.1. Instrumentation. All chemicals are commercially available. The formaldehyde test kits (Aquamerck No. 1.08028, based on the purpald reaction, and Spectroquant No. 1.14678 , based on the chromotropic acid reaction), as well as the sulphuric acid (95-97\%) and absolute ethanol,<smiles>[R]C(=O)[OH2+]</smiles>

Aldehyde Purpald Intermediate Water (uncolored) (uncolored)

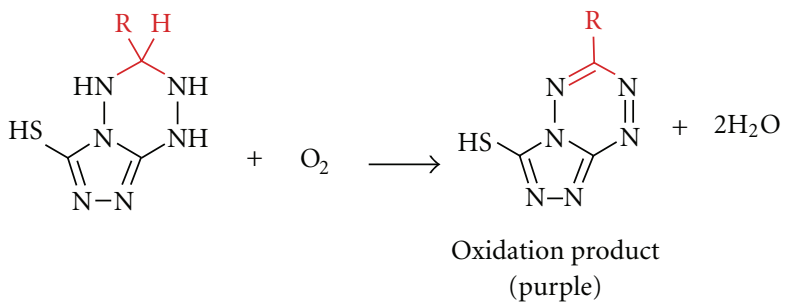

FIGURE 2: Reaction mechanism for the determination of aldehydes using purpald according to Hopps [8].

were purchased from Merck (Darmstadt, Germany). Orthophosphoric acid (85\%) was obtained from Sigma-Aldrich (Taufkirchen Germany). A formaldehyde standard solution ( $200 \mathrm{mg} / \mathrm{L}$ in $40 \%$ vol ethanol) was prepared from a $37 \%$ formaldehyde stock solution (Merck, Darmstadt, Germany) and confirmed by iodometric titration (as specified in the application note supplied with the Spectroquant test kit).

A Vortex Genie 2 mixer (Scientific Industries Inc., Bohemia, NY) was used for homogenization of solutions. Sample temperature was controlled in a DC10-W26 heating circulator bath (Haake, Karlsruhe, Germany). A Vapodest 30 automated distillation device (C. Gerhardt, Fabrik und Lager chemischer Apparate, Bonn, Germany) was used for distillation, with condenser cooling at $1^{\circ} \mathrm{C}$ provided by a recirculating chiller B-740 (Büchi, Flawil, Switzerland). Spectrophotometric measurements were performed on a Perkin Elmer Lambda 12 dual beam spectrometer equipped with an automatic cell changer. The spectrometer was operated with 
the UV WinLab software (version 2.80.03). The spectra were acquired in a range between 350 and $800 \mathrm{~nm}$ at a scanning speed of $120 \mathrm{~nm} / \mathrm{min}$ with a data interval of $1.0 \mathrm{~nm}$. All measurements were made against ethanol $(40 \% \mathrm{vol})$ as a blank.

\subsection{Rapid Screening Using Purpald Reagent. A total of 508} samples of alcoholic beverages (beer, wine, spirits, and unrecorded alcohol; see $[39,40]$ for details on unrecorded alcohol) were analyzed using the purpald method according to the specifications of the test kit. Briefly, $5 \mathrm{~mL}$ of the sample were pipetted into a test tube, and five drops of the alkalinization reagent were added to raise the $\mathrm{pH}$ to a level above 13. Afterwards, the reaction was started by adding a microspoonful of the purpald reagent. The solution was then carefully mixed on the vortex mixer. After a reaction time of five minutes, a purple colour indicated a positive result. Uncoloured solutions indicated the absence of any aldehyde (detection limit at $0.1 \mathrm{mg} / \mathrm{L}$ according to the manufacturer).

\subsection{Quantitative Photometric Determination Using the Chro-} motropic Acid Method. Only samples that showed a positive purpald reaction needed further analysis. Formaldehyde in these was quantified using the chromotropic acid method. Uncoloured samples (e.g., vodka, blanco tequila, fruit spirits) were used without further preparation. Coloured samples (e.g., beer, wine, whiskey) were distilled according to the AOAC method [34]. The distillation was accomplished using an automated steam distillation device (see [4143] for further details on steam distillation in the sample preparation of alcoholic beverages). To ensure consistent experimental conditions, the system was preheated before every startup, running a blank sample at full steam power (according to the manufacturer's instructions). Next, $100 \mathrm{~mL}$ of sample were brought to $20^{\circ} \mathrm{C}$ and pipetted into a $250 \mathrm{~mL}$ Kjeldatherm digestion tube. To prevent evaporation while multiple tests were prepared, the tubes were temporarily sealed using laboratory film. To prepare the receiver, a spatula of crushed ice was placed in a $50 \mathrm{~mL}$ graduated flask before adding $3 \mathrm{~mL}$ of sulphuric acid (25\%). The receiver was then placed underneath the outlet tubing of the distillation device in a beaker filled with ice water to assure cooling during the distillation process (Figure 3 ). Just before clamping the digestion tube into the distillation device, $1 \mathrm{~mL}$ of phosphoric acid (85\%) was added. The automatic distillation was started and run until the calibration mark was nearly reached. After termination, the flask was tightly sealed, the distillate was brought to $20^{\circ} \mathrm{C}$ in a water bath and filled up to the calibration mark with $40 \%$ ethanol.

The chromotropic acid method was performed according to the manufacturer's test kit instructions. A $5 \mathrm{~mL}$ volume of the sulphuric reagent was pipetted into a test tube, and a microspoonful of the chromotropic acid reagent was dissolved by holding the tube in an ultrasonic bath for approximately 120 seconds. A $3 \mathrm{~mL}$ volume of the sample solution or the distillate was then slowly pipetted into the tube. To start the reaction, the hot tube was closed with a screw cap, and the solution was carefully homogenized

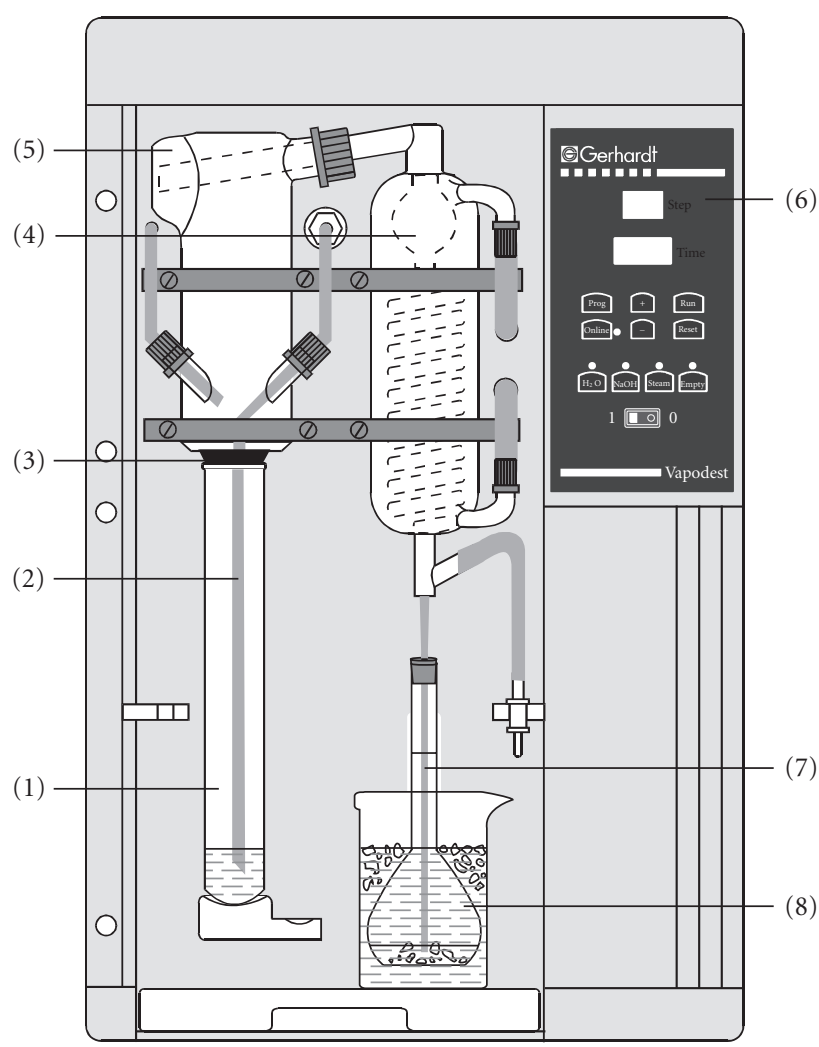

Figure 3: Automated steam distillation device for the determination of formaldehyde in alcoholic beverages: (1) Kjeldatherm digestion tube with acidified sample, (2) steam inlet tubing, (3) Viton-cone, (4) distillation condenser cooled at $1{ }^{\circ} \mathrm{C}$, (5) distribution head, (6) keyboard and display, (7) distillate outlet tubing, and (8) cooled graduated flask as receiver containing ice and sulfuric acid (25\%), in which the outlet tubing must be submerged to avoid losses.

using a vortex mixer. After a reaction time of 10 minutes, the contents of the tube were briefly mixed again. A $2.5 \mathrm{~mL}$ volume of the reaction liquid was transferred into a cuvette for measurement of the absorbance at a wavelength of $565 \mathrm{~nm}$ as well as to record a full spectrum. The calibration was conducted using freshly prepared standards $(0.5,1.0$, $2.0,4.0,8.0 \mathrm{mg} / \mathrm{L}$ in vodka $40 \% \mathrm{vol}$ ) treated similarly to the samples.

\subsection{Multivariate Analysis to Improve Quantitative Photom-} etry. In preliminary experiments with pure standards, no interference was noted for the chromotropic acid method even if acetaldehyde was present in large excess. However while analysing real samples, we noted interferences of other compounds that led to yellowing/browning of the solution. For many samples, the signals created by these matrix compounds were sometimes relatively large and more or less overlapped the formaldehyde peak. For this reason, calibration on a single wavelength $(565 \mathrm{~nm})$ is not recommended for formaldehyde quantification in alcoholic beverages. Instead, we evaluated different multivariate techniques such as multivariate curve resolution (MCR) or 
independent component analysis (ICA). These methods are able to extract the target spectrum from a complex matrix and therefore could improve the analytical procedure to determine formaldehyde in alcoholic beverages.

Much research in recent years has been done to solve the mixture analysis problem and to extract real spectra and concentration profiles from overlapping spectral data without any a priori assumptions about the composition of the system [44-48].

Nowadays, the MCR-ALS (Multivariate Curve Resolution-Alternating Least Squares) method developed by Tauler $[46,49,50]$ is the most well-known and frequently used self-modelling algorithm for spectral deconvolution $[44,51]$. Results of this method can be considerably improved by applying contraints based on the previous knowledge about the system studied (e.g., nonnegativity, closure, unimodality) [46]. Previous examples in food analysis include the determination of vitamins, food colours, alcohols, and dairy products $[44,52-54]$.

Another set of approaches for multivariate analysis is known as "independent component analysis" (ICA) [55, 56]. In some interpretations, ICA can be considered as an extension of principal component analysis (PCA), the basis of many chemometric methods. ICA methods differ in numerical measures of statistical independence and approximations. The MILCA algorithm (Mutual Information Least Dependent Component Analysis) is employed in the present study. This algorithm possesses some unique properties that make it advantageous in comparison with other ICA techniques [57]. MILCA is based on the search for the least dependent (in contrast to independent) mixture components gauged by precise numerical estimates of mutual information [58] as a measure of signal dependence. It was found that MILCA outperforms other specialized chemometric algorithms for spectra decomposition problems and can be used for, for example, the analysis of vitamins $[47,52]$ and human brain samples [57].

The third algorithm we apply is SIMPLISMA (Simpleto-use-Interactive-Self-Modelling-Mixture-Analysis) [59], which belongs to the pure variable selection methods. It finds the most representative row or column profiles for the different compounds in the data set. When the selectivity conditions are favourable, the row or column can be directly associated with the pure concentration or response profile and the successful resolution of the mixture can be achieved.

For MCR calculation we used the software Unscrambler $\mathrm{X}$ version 10.0.1 (Camo Software AS, Oslo, Norway). We applied nonnegativity constraints during the ALS optimization. For the ICA calculations, we used Matlab v. 7.0 (The Math Works, Natick, Mass, USA). We applied the SIMPLISMA [59] and MILCA [58] algorithms. The data set for analysis comprised of the 321 alcoholic beverages tested positive in the purpald assay. To assess the similarities between the resolved and the experimental spectra, we used Pearson's correlation coefficient $(R)$.

2.5. Quantum-Chemical Calculations for Structure Elucidation. HyperChem Professional (Hypercube, Gainesville, Fla,
USA) software package (v.8.0) was used for quantum chemical calculations. The main goal of all quantum-chemical methods is the solving of the Schrödinger equation. In this case based on the Hartree-Fok-Rutan equation by the selfconsistent field (SCF) method, we applied the semiempirical PM3 (Parametrised Model 3) method for calculation with full geometry optimization. In most cases it is the most accurate semiempirical method. The main approaches of the PM3 method include adiabatic, one-electron, MO LCAO (molecular orbital as a linear combination of atomic orbitals) and INDO (Intermediate Neglect of Differential Overlap) approximations. For UV-VIS spectra calculation, we used 5 occupied and unoccupied orbitals using the configuration interaction (CI) method. For details regarding the calculations, see [60].

${ }^{13} \mathrm{C}$ NMR spectra calculations were carried out using ChemBioDraw 12.0 software (CambridgeSoft, Cambridge, UK). Chemical shifts are estimated for all hydrogens or carbon atoms for which additivity rules are available. Following a hierarchical list, the algorithm first identifies key substructures of a molecule. A substructure provides the base value for the estimated shift. The ${ }^{13} \mathrm{C}$ NMR Shift tool is based on 4000 parameters. It also implements models for ethylenes (cis/trans) and cyclohexanes (equatorial/axial). In case of

${ }^{13} \mathrm{C}$ NMR, it estimates over $95 \%$ of the shifts with a mean deviation of $0.29 \mathrm{ppm}$ and standard deviation of $2.8 \mathrm{ppm}$. For details, see $[61,62]$.

\section{Results and Discussion}

3.1. Purpald Screening. In the first stage of the project, we evaluated the purpald test kit for use with alcoholic beverages (the test kit was originally intended for disinfectant and rinsing solutions (e.g., laundries) and aqueous solutions). We have spiked vodka samples $(40 \%$ vol) with different concentrations of formaldehyde and acetaldehyde and not only visually examined the colour reaction but also made a spectrophotometric measurement of the full visible light spectrum. Our results show that the purpald assay is usable with alcoholic solutions, and we were able to confirm the manufacturer's detection limit of $0.1 \mathrm{mg} / \mathrm{L}$. While it was recognized that the absorption maxima of different aldehydes are too close to allow their differentiation [38], we are the first to quantitatively record differences in sensitivity between formaldehyde and acetaldehyde (the assay is approximately 20 times more sensitive for formaldehyde than for acetaldehyde (Figure 4(a))). As many alcoholic beverages (i.e., especially beer, vodka, or rum) contain less than $20 \mathrm{mg} / \mathrm{L}$ of acetaldehyde [9], the specificity of this assay is suitable to select formaldehyde-positive samples without an unacceptably high number of false-positives. Although we were able to exclude more than $50 \%$ of the original samples as being free of formaldehyde or any other aldehyde detectable with purpald (Figure 5), the assay does not allow us to conclude that a product in fact does contain formaldehyde, so that a more specific confirmation is then needed. Nevertheless, we think that the strategy to screen the samples with purpald is worthwhile, as the assay is very 


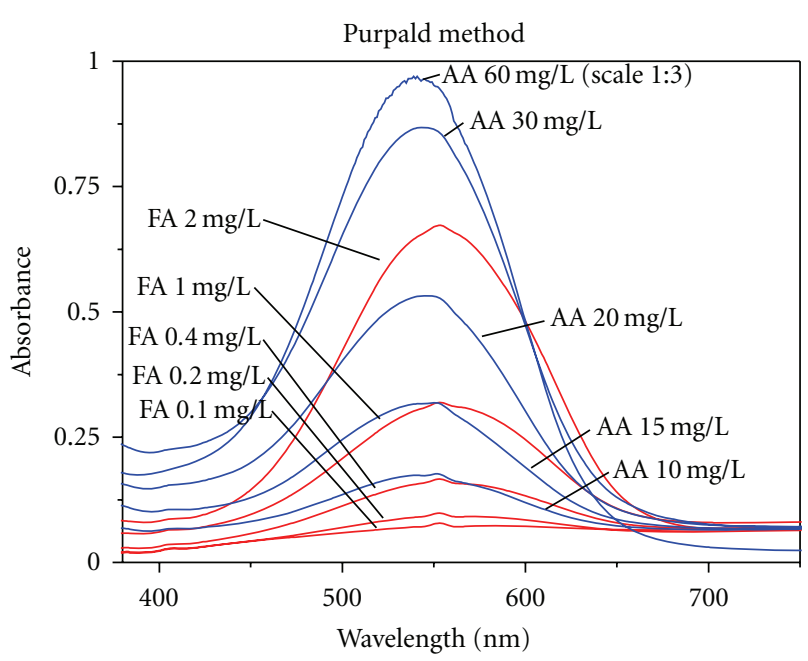

(a)

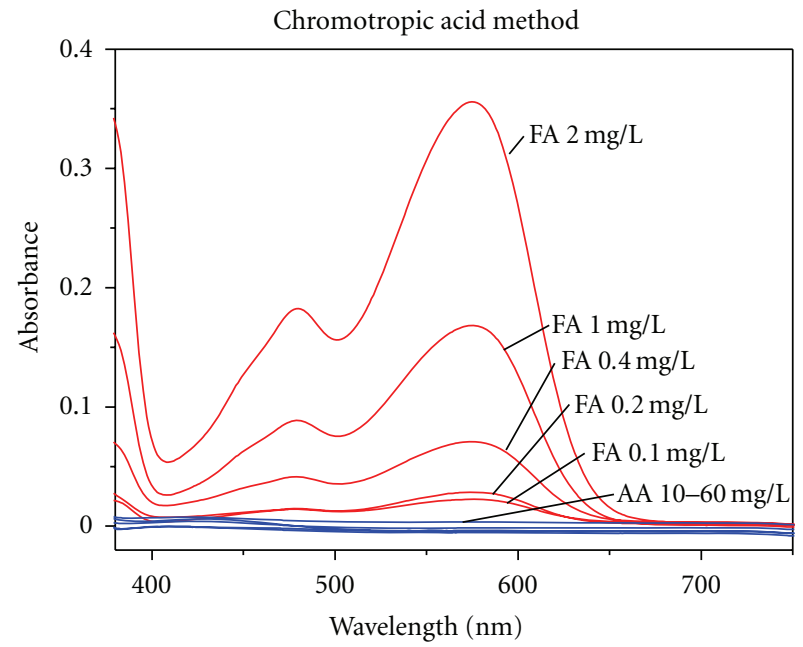

(b)

FIGURE 4: VIS-Spectra of formaldehyde (FA) and acetaldehyde (AA) reaction products with purpald (a) and chromotropic acid (b).

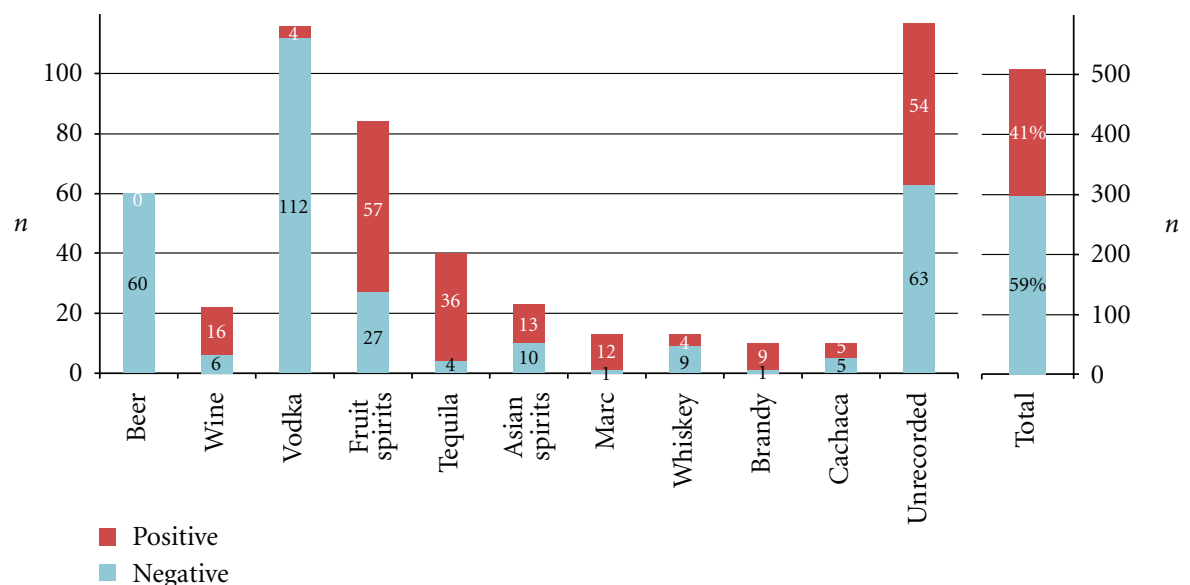

FIGURE 5: Results of the screening using purpald reagent.

quick, and it allowed us to screen over 500 samples in 3 weeks, which is more than what we had originally intended.

\subsection{Chromotropic Acid Confirmation Analysis: Remarks on} Operating Procedure and Detection Limits. To confirm the presence of formaldehyde in the samples, we chose the chromotropic acid procedure, which is suggested by AOAC for general use in food analysis [34]. In contrast to the operating procedure of $\mathrm{Li}$ et al. [63], we used an automated steam distillation device, as suggested by Steiner and Länzlinger [64] or Liu [65]. In deviation from most previous protocols, the commercial test kit [66] does not require heating of the reagent solution in a water bath (the heat derived from the dilution of sulphuric acid is sufficient to form the violet dye, as also suggested by Steiner et al. [67] for optimization of the assay). Our detection limit $(0.09 \mathrm{mg} / \mathrm{L}$ in vodka) is similar to that reported in the specifications of the test kit [66] $(0.10 \mathrm{mg} / \mathrm{L}$ for $10 \mathrm{~mm}$ cells $)$, and to that reported by Donhauser et al. [68] $(0.1 \mathrm{mg} / \mathrm{L})$, while Li et al. [63] $(0.033 \mathrm{mg} / \mathrm{L})$ and Kleinert and Srepel [69] $(0.02 \mathrm{mg} / \mathrm{L})$ reported lower, and Krüger and Holländer [70] $(0.25 \mathrm{mg} / \mathrm{L})$ reported slightly higher limits. Of course, techniques using chromatographic separation offer limits in the lower $\mu \mathrm{g} / \mathrm{L}$ range, but we feel that our limit is sufficient because it is over a factor of 20 lower than the WHO IPCS tolerable concentration of $2.6 \mathrm{mg} / \mathrm{L}$ [4]. It is also lower than the EU limit for total aldehydes in vodka $(0.5 \mathrm{~g} / \mathrm{hL}$ of pure alcohol, which is $2 \mathrm{mg} / \mathrm{L}$ for a $40 \% \mathrm{vol}$ spirit).

3.3. Chromotropic Acid-Formaldehyde Reaction: Structure Elucidation. It is rather surprising that the nature of the chromogen of such a widely used analytical procedure such as the reaction of chromotropic acid with formaldehyde has never been unambiguously proven [7]. According to a hypothesis of Georghiou and Ho [7], the actual product would be the monocationic dibenzoxanthylium structure, 


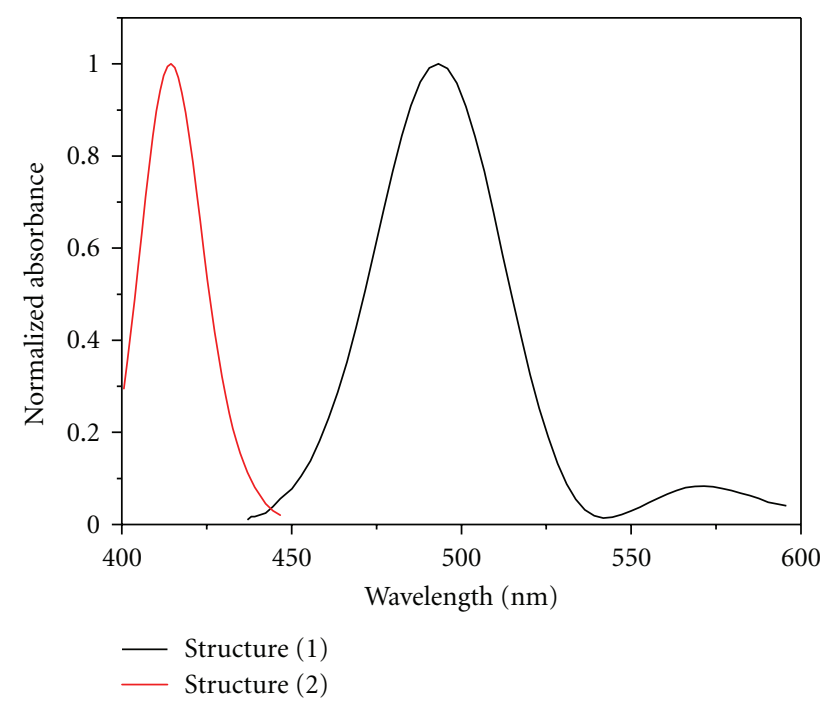

FIgURE 6: Calculated UV-VIS spectra of the possible reaction products of the chromotropic acid-formaldehyde reaction. Structure (1): monocationic dibenzoxanthylium structure; structure (2): para,para-quinoidal structure (for structural formulae see Figure 1).

while the most often quoted structure (e.g., $[35,71]$ ) of the chromogen appears to be the very unlikely para,paraquinoidal structure (Figure 1). However, as their attempt to crystallize the adduct was unsuccessful, the final structure remains unverified [7]. To decide, which structure is more likely, we did semiempirical quantum chemical calculations of the UV-VIS spectra of the two possible adducts of the reaction (Figure 4(b)). It has been found that the maxima of the spectral bands for the monocationic dibenzoxanthylium structure are 493 and $563 \mathrm{~nm}$, which is very similar to the experimental values (first peak around 470-490 and second peak around 560-580) (Figure 6). The correlation coefficient between the calculated spectrum and the experimental spectral data is relatively high $(R=0.81)$. On the other hand, there is no singlet peak in the region of $560-580 \mathrm{~nm}$ for the para,para-quinoidal structure, and the correlation is considerably lower $(R=0.44)$. Additionally, the spatial situation appears to add to the unlikelihood of the formation of the para,para-quinoidal structure. Calculation of ${ }^{13} \mathrm{C} N M R$ spectra revealed that the monocationic dibenzoxanthylium structure would have two peaks at 119 and $33 \mathrm{ppm}$ that are comparable with experimental data from the literature (119 and $27 \mathrm{ppm}$ [7]). The para,para-quinoidal structure would have a peak at $115 \mathrm{ppm}$ but no signal around $30 \mathrm{ppm}$. Our UV-VIS and ${ }^{13} \mathrm{C}$ NMR calculations provide evidence that it is most likely that the monocationic dibenzoxanthylium is formed. Our data, therefore, confirm the hypothesis of Georghiou [7].

\subsection{Chromotropic Acid-Formaldehyde Reaction: Interferences.} Regarding the chromotropic acid reaction, the literature is not consistent regarding its specificity towards formaldehyde. The original investigation of Eegriwe [35] found no reaction with acetaldehyde or several other aldehydes and further substances. For determination in alcoholic beverages, it is especially advantageous to have a method in which acetaldehyde, methanol, formic acid, acetic acid, and sugars do not interfere, even if present in the proportion of $10: 1$ or more [72]. The specificity of the chromotropic assay towards formaldehyde has been experimentally confirmed by several authors [63, 69, 73, 74]. Only Ahonen et al. [75] detected an interference of acetaldehyde, leading to a lower finding of formaldehyde ( $88 \%$ at $1 \mathrm{mg} / \mathrm{L}$ of formaldehyde if acetaldehyde was contained in the solution in excess). In our experiments, no interference was noted even if acetaldehyde was present in large excess (Figure 4(b)). However, we noted interferences of other compounds that led to yellowing of the solution. The signals created by these compounds were sometimes relatively large and more or less overlapped the formaldehyde peak. For this reason, we do not recommend quantification using calibration on a single wavelength $(565 \mathrm{~nm})$, but instead suggest that a multivariate technique has to be used.

3.5. Chromotropic Acid-Formaldehyde Reaction: Multivariate Curve Deconvolution and Quantitative Results. The multivariate models that best describe the investigated system consist of three pure compounds for all chemometric methods used. Compared to a set of pure compound spectra (Figure 7(a)), the resolved MCR-ALS spectra are shown in Figure $7(\mathrm{~b})$. It can be seen that one spectrum corresponds to the adduct of formaldehyde-chromotropic acid and the other two belong to interferences. Clearly, the interfering substances strongly absorb at $565 \mathrm{~nm}$ and prevent to get accurate results in the single wavelength method. Very similar results were obtained with the two ICA algorithms (Figures 7(c) and 7(d)).

To compare the performance of the different algorithms, we calculated the correlation coefficients $(R)$ between the experimental spectrum of the adduct of formaldehydechromotropic acid reaction and the resolved signals. The SIMPLISMA algorithm gives the best estimation of the spectral signal $(R=0.97)$. However, ALS $(R=0.90)$ and MILCA $(R=0.95)$ are equally suitable for extracting the pure formaldehyde spectrum. For our final evaluation of the samples (Table 1), we decided to use MCR-ALS as this is implemented in our standard statistical software package.

The precision and accuracy of the method were sufficient for the purpose. The coefficient of variation (CV) for spiked vodka $(n=6)$ was $8.2 \%$ at $1 \mathrm{mg} / \mathrm{L}, 4.2 \%$ at $4 \mathrm{mg} / \mathrm{L}$, and $7.9 \%$ at $8 \mathrm{mg} / \mathrm{L}$; the recovery for spiked vodka was $101 \%$ at $1 \mathrm{mg} / \mathrm{L}, 99 \%$ at $4 \mathrm{mg} / \mathrm{L}$, and $99 \%$ at $8 \mathrm{mg} / \mathrm{L}$. For an authentic Asian spirit containing $6.4 \mathrm{mg} / \mathrm{L}$ of formaldehyde, the CV was $4.6 \%(n=6)$. For the purpose of this survey, we have not conducted further validation studies in other matrices, but would recommend to study the measurement uncertainty in more detail if results should be used in expert opinions (e.g., in legal cases against manufacturers if limits are exceeded).

In total, formaldehyde was confirmed in 132 samples (Table 1). The false positive rate of the purpald assay was $37 \%$. The highest incidence was found in tequila $(83 \%)$, Asian spirits (59\%), grape marc (54\%), and brandy (50\%). 


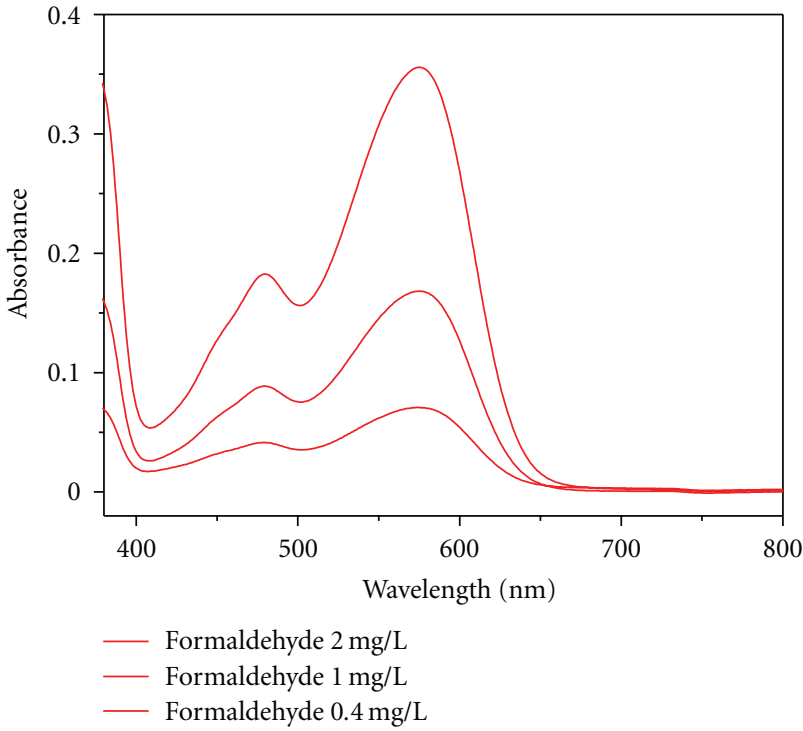

(a)

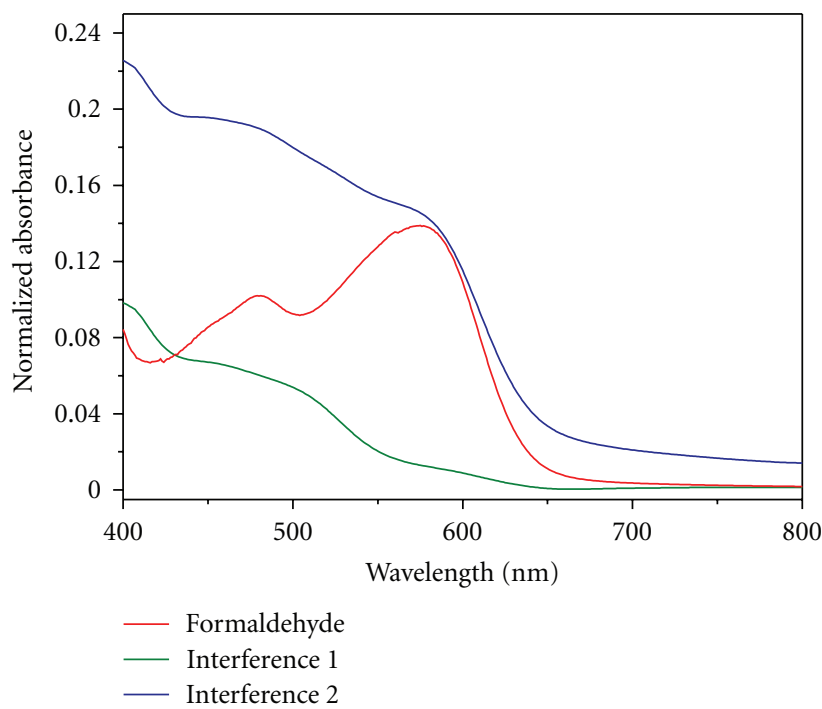

(c)

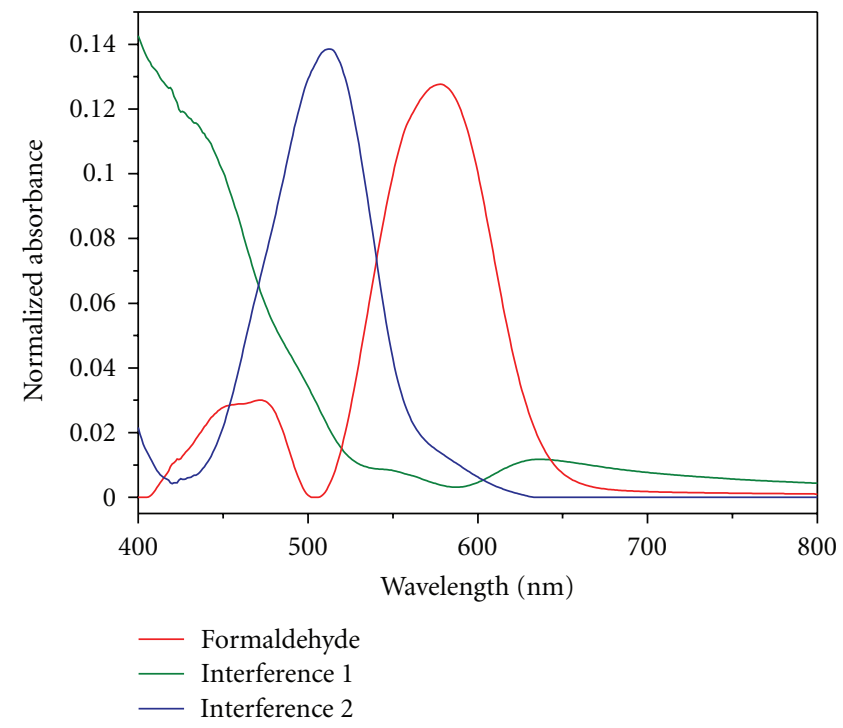

(b)

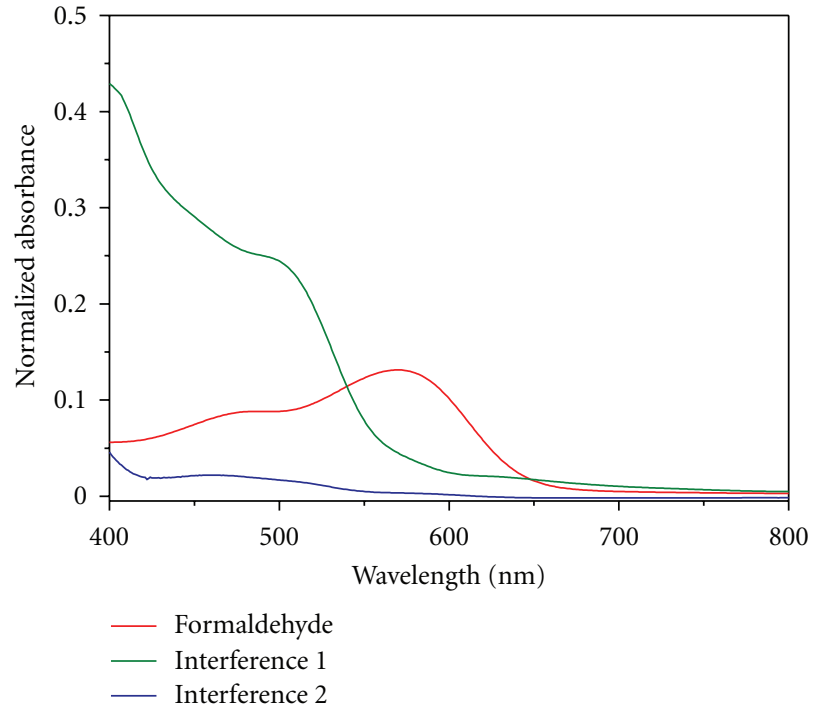

(d)

Figure 7: Experimental pure formaldehyde spectra (a) and resolved MCR-ALS (b), MILCA (c), and SIMPLISMA (d) spectra of formaldehyde and two interferences.

Interestingly, formaldehyde levels were not correlated with ethanol $(P=.51)$, acetaldehyde $(P=.24)$, or methanol $(P=.94)$ levels that had been determined previously using reference procedures [12].

We think that the chromotropic acid reaction along with multivariate curve deconvolution is applicable for the purpose to provide a fast and cheap analysis, for example, in the context of high-throughput screening for occurrence and exposure assessment. We think that only in the case of very high contents of formaldehyde, which would exceed international levels (e.g., the WHO IPCS tolerable concentration (TC) of $2.6 \mathrm{mg} / \mathrm{L} \mathrm{[4]} \mathrm{in} \mathrm{ingested} \mathrm{products),}$ additional chromatographic confirmatory analysis is needed prior to taking measures against producers.

\section{Conclusions}

In this paper we show how it is possible to quickly survey a large number of samples using a two-step procedure: purpald screening followed by quantitative spectrophotometry using chromotropic acid. We can confirm the suitability of the chromotropic acid reaction for the determination of formaldehyde in alcoholic beverages, giving results similar to those of $\mathrm{Li}$ et al. [63]. It is no wonder that the chromotropic acid method is still widely used, as it is simple and inexpensive [76]. As we have shown, the procedure can be improved by using multivariate curve deconvolution, which expands its use to matrices that would be normally excluded due to spectral interferences. In our case, we would 
TABLE 1: Results of the quantitative determination using chromotropic acid.

\begin{tabular}{|c|c|c|c|c|c|c|c|c|c|}
\hline $\begin{array}{l}\text { Sample } \\
\text { category }\end{array}$ & $\begin{array}{l}\text { Total } \\
\text { number } \\
\text { tested }\end{array}$ & $\begin{array}{l}\text { Positive } \\
\text { samples }\end{array}$ & $\begin{array}{l}\text { Average } \\
(\mathrm{mg} / \mathrm{L})\end{array}$ & $\begin{array}{l}\text { Standard } \\
\text { deviation } \\
(\mathrm{mg} / \mathrm{L})\end{array}$ & $\mathrm{P} 90(\mathrm{mg} / \mathrm{L})$ & P95 (mg/L) & P99 (mg/L) & $\underset{(\mathrm{mg} / \mathrm{L})}{\text { Maximum }}$ & $\begin{array}{l}\text { Samples } \\
\text { above limit } \\
(2.6 \mathrm{mg} / \mathrm{L})\end{array}$ \\
\hline Beer & 60 & $0 \%$ & - & - & - & - & - & - & 0 \\
\hline Wine & 22 & $41 \%$ & 0.13 & 0.29 & 0.37 & 0.54 & 1.03 & 1.15 & 0 \\
\hline Vodka & 115 & $0 \%$ & - & - & - & - & - & - & 0 \\
\hline Fruit spirits & 85 & $44 \%$ & 0.20 & 0.61 & 0.39 & 0.68 & 1.77 & 5.39 & 1 \\
\hline Tequila & 40 & $83 \%$ & 0.70 & 1.22 & 1.77 & 2.87 & 5.26 & 6.06 & 2 \\
\hline Asian spirits & 23 & $59 \%$ & 2.26 & 4.60 & 9.75 & 13.44 & 14.21 & 14.37 & 4 \\
\hline Marc & 13 & $54 \%$ & 0.49 & 0.86 & 1.66 & 2.20 & 2.64 & 2.75 & 1 \\
\hline Whiskey & 13 & $31 \%$ & 0.20 & 0.46 & 0.55 & 1.03 & 1.50 & 1.62 & 0 \\
\hline Brandy & 10 & $50 \%$ & 0.09 & 0.61 & 1.15 & 1.41 & 1.62 & 1.67 & 0 \\
\hline Cachaça & 10 & $20 \%$ & 0.10 & 0.26 & 0.21 & 0.51 & 0.76 & 0.99 & 0 \\
\hline Unrecorded & 117 & $29 \%$ & 0.22 & 0.71 & 0.72 & 1.08 & 1.56 & 6.71 & 1 \\
\hline Total sample & 508 & $26 \%$ & 0.27 & 1.21 & 0.70 & 1.11 & 6.14 & 14.37 & 9 \\
\hline
\end{tabular}

go so far to say that the determination of formaldehyde in alcoholic beverages using chromotropic acid is not possible without a chemometric method. The advantage of the overall procedure is that it is simple, reliable and cheaper than chromatographic methods.

It should be noted that this approach for the determination of a target compound in a complex matrix with interferences is transferable to other similar spectrophotometric problems. Chemometric approaches can be used for any reaction where the signal of the target compound overlaps with interferences. We expect that, as these methods become more and more integrated into standard statistical software packages, their use will considerably increase in the future.

Our survey of about 500 products showed that only $1.8 \%$ of the samples had formaldehyde levels above the WHO IPCS tolerable concentration. A $60 \mathrm{~kg}$ person would need to consume $0.8 \mathrm{~L}$ of alcohol at $14.37 \mathrm{mg} / \mathrm{L}$ daily to exceed the US EPA RfD of $0.2 \mathrm{mg} / \mathrm{kg}$ bodyweight/day, which is extremely unlikely even in this worst-case scenario. While a more detailed population based risk assessment is needed, which also should include other foods, we preliminarily conclude that formaldehyde is unlikely to pose an additional risk for the alcohol drinking population.

\section{Acknowledgments}

The authors are grateful to a combined DAAD (German Academic Exchange Service) and Russian Ministry of Education grant (no. 2.2.2.3/9033) for the financial support to YBM. The authors warmly thank Hannelore Heger for the excellent technical assistance. Jenny Leitz and Anja Stoppa are thanked for contributing to the method validation. The sampling of some of the unrecorded alcohols studied in this paper was financed by the European Commission Seventh Framework Programme Project AMPHORA (Alcohol Measures for Public Health Research Alliance), Project no. 223059, granted to the Hospital Clinic de Barcelona (http://www.amphoraproject.net/). Jürgen Rehm
(CAMH, Toronto) is thanked for providing further samples of unrecorded alcohol.

\section{References}

[1] IARC, "Formaldehyde, 2-butoxyethanol and 1-tert-butoxypropan-2-ol," IARC Monographs on the Evaluation of Carcinogenic Risks to Humans, vol. 88, pp. 39-325, 2006.

[2] R. Baan, Y. Grosse, K. Straif et al., "A review of human carcinogens-part F: chemical agents and related occupations," The Lancet Oncology, vol. 10, no. 12, pp. 1143-1144, 2009.

[3] US-EPA, "Formaldehyde (CASRN 50-00-0). Integrated Risk Information System," Document 0419, U.S. Environmental Protection Ageny, Washington, DC, USA, 1998.

[4] IPCS, "Formaldehyde. Concise international chemical assessment document 40," Tech. Rep., World Health Organization, Geneva, Switzerland, 2002.

[5] H. P. Til, R. A. Woutersen, and V. J. Feron, "Evaluation of the oral toxicity of acetaldehyde and formaldehyde in a 4-week drinking-water study in rats," Food and Chemical Toxicology, vol. 26, no. 5, pp. 447-452, 1988.

[6] V. J. Feron, H. P. Til, F. De Vrijer, R. A. Woutersen, F. R. Cassee, and P. J. Van Bladeren, "Aldehydes: occurrence, carcinogenic potential, mechanism of action and risk assessment," Mutation Research, vol. 259, no. 3-4, pp. 363-385, 1991.

[7] P. E. Georghiou and C. K. J. Ho, "The chemistry of the chromotropic-acid method for the analysis of formaldehyde," Canadian Journal of Chemistry, vol. 67, no. 5, pp. 871-876, 1989.

[8] H. B. Hopps, "Purpald(R): a reagent that turns aldehydes purple!," Aldrichimica Acta, vol. 33, no. 1, pp. 28-30, 2000.

[9] D. W. Lachenmeier and E. M. Sohnius, "The role of acetaldehyde outside ethanol metabolism in the carcinogenicity of alcoholic beverages: evidence from a large chemical survey," Food and Chemical Toxicology, vol. 46, no. 8, pp. 2903-2911, 2008.

[10] D. W. Lachenmeier, F. Kanteres, and J. Rehm, "Carcinogenicity of acetaldehyde in alcoholic beverages: risk assessment outside ethanol metabolism," Addiction, vol. 104, no. 4, pp. 533-550, 2009. 
[11] D. W. Lachenmeier, F. Kanteres, and J. Rehm, "Epidemiologybased risk assessment using the benchmark dose/margin of exposure approach: the example of ethanol and liver cirrhosis," International Journal of Epidemiology, vol. 40, no. 1, pp. 210-218, 2011.

[12] European Commission, "Commission Regulation (EC) No 2870/2000 laying down Community reference methods for the analysis of spirits drinks," Official Journal of the European Communities, vol. L333, pp. 20-46, 2000.

[13] M. N. Lau, J. D. Ebeler, and S. E. Ebeler, "Gas chromatographic analysis of aldehydes in alcoholic beverages using a cysteamine derivatization procedure," American Journal of Enology and Viticulture, vol. 50, no. 3, pp. 324-333, 1999.

[14] H. Miyakawa, K. Fujinuma, and K. Kamata, "Determination of formaldehyde in beer," Annual Report of Tokyo Metropolitan Institute of Public Health, vol. 58, pp. 185-188, 2007.

[15] Y. S. Park, Y. J. Lee, and K. T. Lee, "Analysis of formaldehyde and acetaldehyde in alcoholic beverage," Journal of The Korean Society of Food Science and Nutrition, vol. 35, no. 10, pp. 14121419, 2006.

[16] J. Curyło and W. Wardencki, "HS-SPME-CGC-PID determination of aldehydes in rectified spirits and vodkas after derivatisation with 2,4,6-trichlorophenylhydrazine (TCPH)," Chemia Analityczna, vol. 50, no. 4, pp. 735-748, 2005.

[17] P. Sowiński, W. Wardencki, and M. Partyka, "Development and evaluation of headspace gas chromatography method for the analysis of carbonyl compounds in spirits and vodkas," Analytica Chimica Acta, vol. 539, no. 1-2, pp. 17-22, 2005.

[18] Q. J. Wu, H. Lin, W. Fan, J. J. Dong, and H. L. Chen, "Investigation into benzene, trihalomethanes and formaldehyde in Chinese lager beers," Journal of the Institute of Brewing, vol. 112, no. 4, pp. 291-294, 2006.

[19] J. Curyło and W. Wardencki, "Application of single drop extraction (SDE) gas chromatography method for the determination of carbonyl compounds in spirits and vodkas," Analytical Letters, vol. 39, no. 13, pp. 2629-2642, 2006.

[20] W. Wardencki, P. Sowiński, and J. Curyło, "Evaluation of headspace solid-phase microextraction for the analysis of volatile carbonyl compounds in spirits and alcoholic beverages," Journal of Chromatography A, vol. 984, no. 1, pp. 89-96, 2003.

[21] E. A. de Oliveira and J. B. de Andrade, "Simultaneous determination of formaldehyde and acetaldehyde and their respective hydroxyalkylsulfonic acids by HPLC," Quimica Nova, vol. 17, no. 1, pp. 13-16, 1994.

[22] J. B. de Andrade, J. N. Reis, M. V. Rebouças, H. L. C. Pinheiro et al., "Determination of formaldehyde and acetaldehyde in drinking water and alcoholic beverages by high performance liquid chromatography (HPLC)," Quimica Analitica, vol. 15, no. 2, pp. 144-147, 1996.

[23] L. C. de Azevedo, M. M. Reis, G. E. Pereira, G. O. Da Rocha, L. A. Silva, and J. B. De Andrade, "A liquid chromatographic method optimization for the assessment of low and high molar mass carbonyl compounds in wines," Journal of Separation Science, vol. 32, no. 20, pp. 3432-3440, 2009.

[24] J. C. Pires Penteado, A. C. Sobral, and J. C. Masini, "Evaluation of monolithic columns for determination of formaldehyde and acetaldehyde in sugar cane spirits by high-performance liquid chromatography," Analytical Letters, vol. 41, no. 9, pp. 1674-1681, 2008.

[25] G. Burini and R. Coli, "Determination of formaldehyde in spirits by high-performance liquid chromatography with diode-array detection after derivatization," Analytica Chimica Acta, vol. 511, no. 1, pp. 155-158, 2004.
[26] J. F. Lawrence and J. R. Iyengar, "The determination of formaldehyde in beer and soft drinks by HPLC of the 2,4dinitrophenylhydrazone derivative," International Journal of Environmental Analytical Chemistry, vol. 15, no. 1, pp. 47-52, 1983.

[27] R. J. Elias, V. F. Laurie, S. E. Ebeler, J. W. Wong, and A. L. Waterhouse, "Analysis of selected carbonyl oxidation products in wine by liquid chromatography with diode array detection," Analytica Chimica Acta, vol. 626, no. 1, pp. 104-110, 2008.

[28] D. M. Rodríguez, K. Wrobel, and K. Wrobel, "Determination of aldehydes in tequila by high-performance liquid chromatography with 2,4-dinitrophenylhydrazine derivatization," European Food Research and Technology, vol. 221, no. 6, pp. 798-802, 2005.

[29] O. M. Sampaio, R. V. Reche, and D. W. Franco, "Chemical profile of rums as a function of their origin. The use of chemometric techniques for their identification," Journal of Agricultural and Food Chemistry, vol. 56, no. 5, pp. 1661-1668, 2008.

[30] R. F. Nascimento, J. C. Marques, B. S. Lima Neto, D. De Keukeleire, and D. W. Franco, "Qualitative and quantitative high-performance liquid chromatographic analysis of aldehydes in Brazilian sugar cane spirits and other distilled alcoholic beverages," Journal of Chromatography A, vol. 782, no. 1, pp. 13-23, 1997.

[31] X. Q. Zhao and Z. Q. Zhang, "Microwave-assisted online derivatization for sensitive flow injection fluorometric determination of formaldehyde in some foods," Talanta, vol. 80, no. 1, pp. 242-245, 2009.

[32] X. Q. Zhao and Z. Q. Zhang, "Rapid and sensitive determination of formaldehyde in some beverages and foods by flowinjection fluorimetric analysis," International Journal of Food Science and Technology, vol. 44, no. 1, pp. 216-221, 2009.

[33] F. S. de Oliveira, E. T. Sousa, and J. B. de Andrade, "A sensitive flow analysis system for the fluorimetric determination of low levels of formaldehyde in alcoholic beverages," Talanta, vol. 73, no. 3, pp. 561-566, 2007.

[34] AOAC, AOAC Official Methods of Analysis, AOAC, Arlington, Va, USA, 1995.

[35] E. Eegriwe, "Reaktionen und Reagenzien zum Nachweis organischer Verbindungen IV. Formaldehyd," Fresenius' Journal of Analytical Chemistry, vol. 110, no. 1, pp. 22-25, 1937.

[36] H. Brandl, "4-Amino-3-hydrazino-5-mercapto-4H-1,2,4-triazol (Purpald@) — ein neues sensitives Reagenz auf Aldehyde," Praxis der Naturwissenschaften-Chemie, vol. 40, no. 7, pp. 2529, 1991.

[37] R. G. Dickinson and N. W. Jacobsen, "A new sensitive and specific test for the detection of aldehydes: formation of 6mercapto-3-substituted-s-triazolo[4,3-b]-s-tetrazines," Journal of the Chemical Society D: Chemical Communications, no. 24, pp. 1719-1720, 1970.

[38] N. W. Jacobsen and R. G. Dickinson, "Spectrometric assay of aldehydes as 6-mercapto-3-substituted-s-triazolo(4,3-b)-stetrazines," Analytical Chemistry, vol. 46, no. 2, pp. 298-299, 1974.

[39] J. Rehm, F. Kanteres, and D. W. Lachenmeier, "Unrecorded consumption, quality of alcohol and health consequences," Drug and Alcohol Review, vol. 29, no. 4, pp. 426-436, 2010.

[40] D. W. Lachenmeier, R. Godelmann, M. Steiner, B. Ansay, J. Weigel, and G. Krieg, "Rapid and mobile determination of alcoholic strength in wine, beer and spirits using a flowthrough infrared sensor," Chemistry Central Journal, vol. 4, no. 1, p. 5,2010 . 
[41] D. W. Lachenmeier, O. Sviridov, W. Frank, and C. Athanasakis, "Rapid determination of the alcohol content in liqueur emulsions and other spirits using steam distillation and densitometry," Deutsche Lebensmittel-Rundschau, vol. 99, no. 11, pp. 439-444, 2003.

[42] D. W. Lachenmeier, P. A. Burri, T. Fauser, W. Frank, and S. G. Walch, "Rapid determination of alcoholic strength of egg liqueur using steam distillation and oscillation-type densimetry with peristaltic pumping," Analytica Chimica Acta, vol. 537, no. 1-2, pp. 377-384, 2005.

[43] D. W. Lachenmeier, S. G. Walch, and W. Kessler, "Using experimental design to optimise precision of steam distillation for determining alcoholic strength in spirits," European Food Research and Technology, vol. 223, no. 2, pp. 261-266, 2006.

[44] D. W. Lachenmeier and W. Kessler, "Multivariate curve resolution of spectrophotometric data for the determination of artificial food colors," Journal of Agricultural and Food Chemistry, vol. 56, no. 14, pp. 5463-5468, 2008.

[45] A. Kandelbauer, W. Kessler, and R. W. Kessler, "Online UVvisible spectroscopy and multivariate curve resolution as powerful tool for model-free investigation of laccase-catalysed oxidation," Analytical and Bioanalytical Chemistry, vol. 390, no. 5, pp. 1303-1315, 2008.

[46] A. de Juan and R. Tauler, "Multivariate Curve Resolution (MCR) from 2000: progress in concepts and applications," Critical Reviews in Analytical Chemistry, vol. 36, no. 3-4, pp. 163-176, 2006.

[47] Y. B. Monakhova, S. A. Astakhov, A. Kraskov, and S. P. Mushtakova, "Independent components in spectroscopic analysis of complex mixtures," Chemometrics and Intelligent Laboratory Systems, vol. 103, pp. 108-115, 2010.

[48] W. Kessler and R. W. Kessler, "Multivariate curve resolutionintegration of knowledge in chemometric modelsMultivariate curve resolution-integration von wissen in chemometrische modelle," Chemie-Ingenieur-Technik, vol. 82, no. 4, pp. 441$451,2010$.

[49] R. Tauler, A. Smilde, and B. Kowalski, "Selectivity, local rank, 3-way data-analysis and ambiguity in multivariate curve resolution," Journal of Chemometrics, vol. 9, no. 1, pp. 31-58, 1995.

[50] R. Tauler, "Multivariate curve resolution applied to second order data," Chemometrics and Intelligent Laboratory Systems, vol. 30, no. 1, pp. 133-146, 1995.

[51] W. Kessler and R. W. Kessler, "Multivariate curve resolution: a method of evaluating the kinetics of biotechnological reactions," Analytical and Bioanalytical Chemistry, vol. 384, no. 5, pp. 1087-1095, 2006.

[52] Y. U. B. Monakhova, S. P. Mushtakova, S. S. Kolesnikova, and S. A. Astakhov, "Chemometrics-assisted spectrophotometric method for simultaneous determination of vitamins in complex mixtures," Analytical and Bioanalytical Chemistry, vol. 397, no. 3, pp. 1297-1306, 2010.

[53] H. Winning, F. H. Larsen, R. Bro, and S. B. Engelsen, "Quantitative analysis of NMR spectra with chemometrics," Journal of Magnetic Resonance, vol. 190, no. 1, pp. 26-32, 2008.

[54] P. D. A. Pudney, T. M. Hancewicz, and D. G. Cunningham, "The use of confocal Raman spectroscopy to characterise the microstructure of complex biomaterials: foods," Spectroscopy, vol. 16, no. 3-4, pp. 217-225, 2002.

[55] A. Hyvärinen, E. Karhunen, and E. Oja, Independent Component Analysis, John Wiley \& Sons, New York, NY, USA, 2001.
[56] A. Cichocki and S. Amari, Adaptive Blind Signal and Image Processing, Learning Algorithms and Applications, John Wiley \& Sons, New York, NY, USA, 2002.

[57] S. A. Astakhov, H. Stögbauer, A. Kraskov, and P. Grassberger, "Monte Carlo algorithm for least dependent non-negative mixture decomposition," Analytical Chemistry, vol. 78, no. 5, pp. 1620-1627, 2006.

[58] H. Stögbauer, A. Kraskov, S. A. Astakhov, and P. Grassberger, "Least-dependent-component analysis based on mutual information," Physical Review E, vol. 70, no. 6, Article ID 066123, pp. 1-17, 2004.

[59] W. Windig and J. Guilment, "Interactive self-modeling mixture analysis," Analytical Chemistry, vol. 63, no. 14, pp. 14251432, 1991.

[60] J. J. P. Stewart, Encyclopedia of Computational Chemistry, John Wiley \& Sons, New York, NY, USA, 1998.

[61] E. Pretsch, A. Fürst, M. Badertscher, R. Bürgin, and M. E. Munk, "C13Shift: a computer program for the prediction of $\mathrm{C}$ NMR spectra based on an open set of additivity rules," Journal of Chemical Information and Computer Science, vol. 32, pp. 291-295, 1992.

[62] R. Bürgin Schaller, M. E. Munk, and E. Pretsch, "Spectra estimation for computer-aided structure determination," Journal of Chemical Information and Computer Sciences, vol. 36, no. 2, pp. 239-243, 1996.

[63] Y.-L. Li, J. Liu, and W.-S. Guan, "Determination of trace formaldehyde in alcoholic beverages by chromotropic acid spectrophotometry," in Proceedings of the 3rd International Conference on Bioinformatics and Biomedical Engineering (ICBBE '09), p. 1, IEEE Xplore, Beijing, China, 2009.

[64] K. Steiner and U. Länzlinger, "Formaldehyde beer turbidity," Brauerei-Rundschau, vol. 93, no. 3, pp. 37-38, 1982.

[65] Y. Liu, "Determination method for formaldehyde in beer of national standards," Chinese Journal of Public Health Engineering, vol. 8, no. 6, pp. 352-355, 2009.

[66] Merck, "Spectroquant Formaldehyde Test 1.14678.0001 Instructions for use," Merck, Darmstadt, Germany, 2010.

[67] K. Steiner, F. Schur, and H. Pfenninger, "Experiments to detect formaldehyde in beer," Brauwissenschaft, vol. 22, no. 3, pp. 8790, 1969.

[68] S. Donhauser, K. Glas, and G. Walla, "Detection of formaldehyde in beer," Monatsschrift für Brauwissenschaft, vol. 39, no. 10, pp. 364-368, 1986.

[69] T. Kleinert and E. Srepel, "Eine kolorimetrische Bestimmung kleiner Formaldehydmengen mittels Chromotropsäure," Mikrochemie Vereinigt mit Mikrochimica Acta, vol. 33, no. 4, pp. 328-332, 1948.

[70] E. Krüger and H. J. Holländer, "Detection of formaldehyde in beer," Monatsschrift für Brauerei, vol. 21, no. 6, pp. 155-165, 1968.

[71] E. L. R. Krug, "Interference of nitrate in the determination of formaldehyde by the chromotropic acid method," Analytical Chemistry, vol. 49, no. 12, pp. 1865-1867, 1977.

[72] D. A. MacFadyen, "Estimation of formaldehyde in biological mixtures," Journal of Biological Chemistry, vol. 158, no. 1, pp. 107-133, 1945.

[73] J. Knabe, "On the effect of foreign substances on the photometric determination of formaldehyde with chromotropic acid," Archiv der Pharmazie, vol. 297, pp. 312-316, 1964.

[74] F. Gasparini, P. L. Weinert, L. S. Lima, L. Pezza, and H. R. Pezza, "A simple and green analytical method for the 
determination of formaldehyde," Journal of the Brazilian Chemical Society, vol. 19, no. 8, pp. 1531-1537, 2008.

[75] I. Ahonen, E. Priha, and M. L. Aijala, "Specificity of analytical methods used to determine the concentration of formaldehyde in workroom air," Chemosphere, vol. 13, no. 4, pp. 521$525,1984$.

[76] E. Fagnani, C. B. Melios, L. Pezza, and H. R. Pezza, "Chromotropic acid-formaldehyde reaction in strongly acidic media. The role of dissolved oxygen and replacement of concentrated sulphuric acid," Talanta, vol. 60, no. 1, pp. 171176, 2003. 


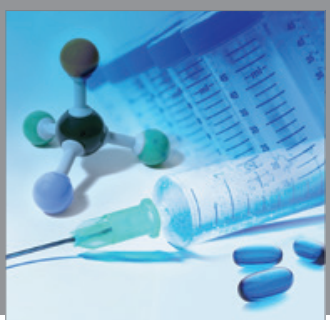

International Journal of

Medicinal Chemistry

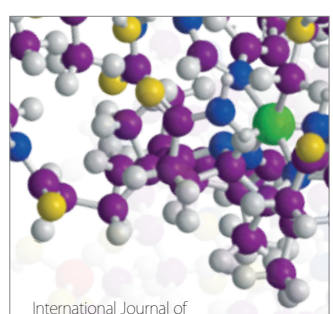

Carbohydrate Chemistry

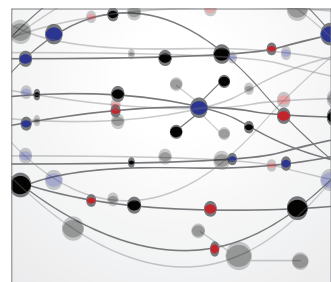

The Scientific World Journal
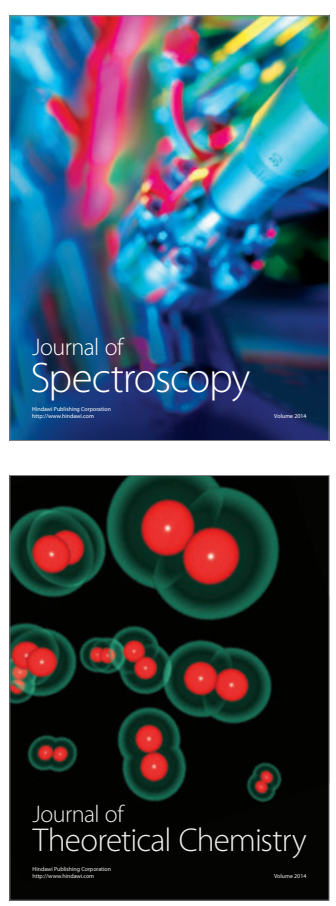
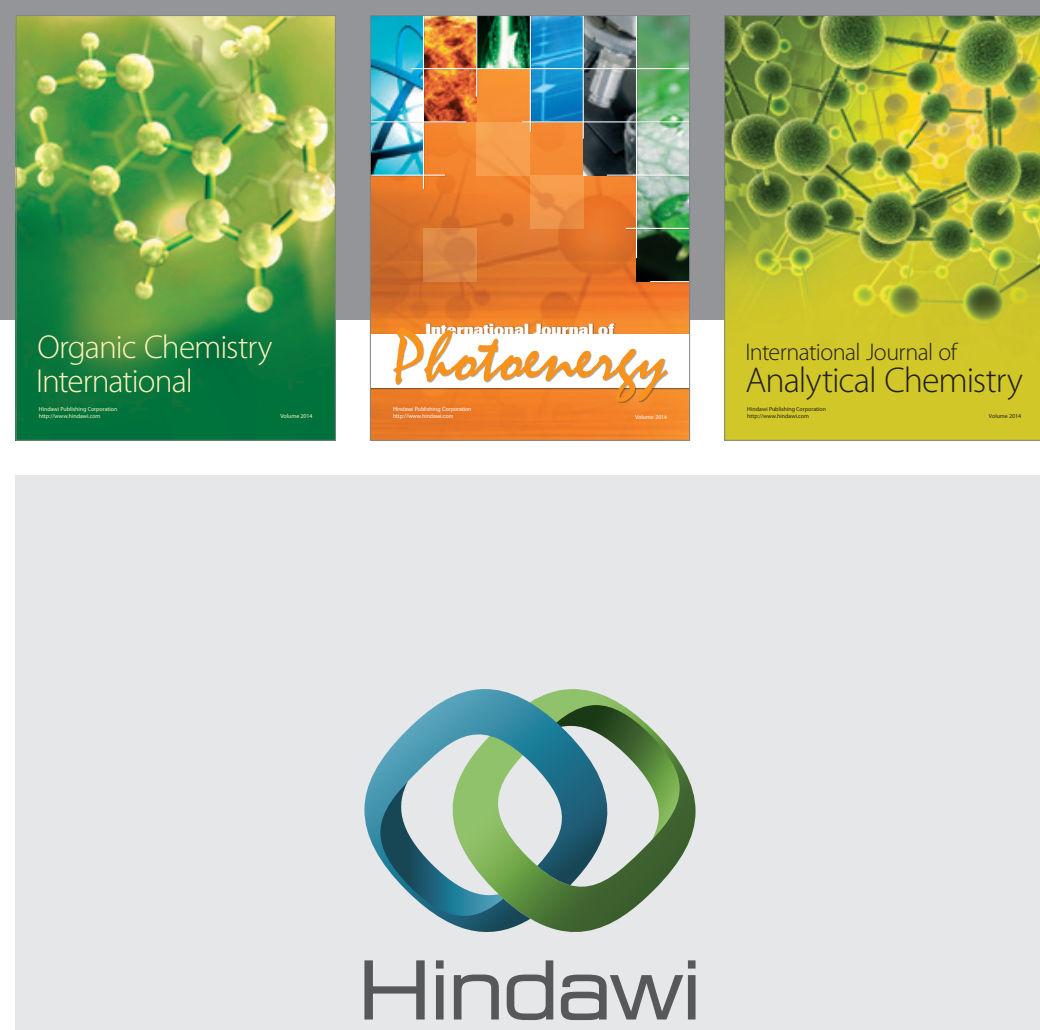

Submit your manuscripts at

http://www.hindawi.com
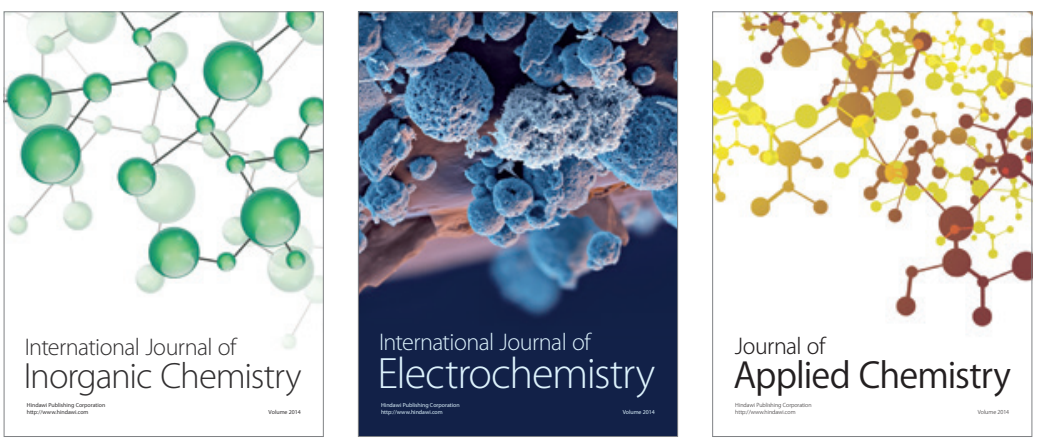

Journal of

Applied Chemistry
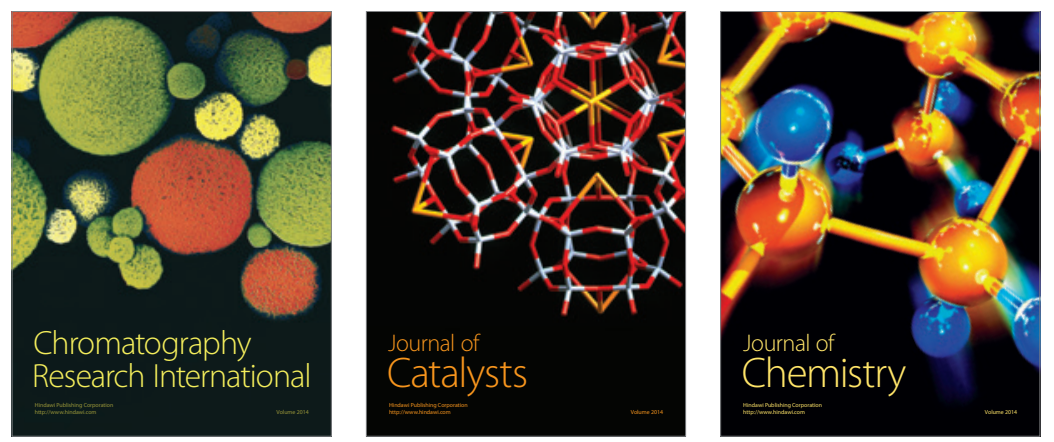
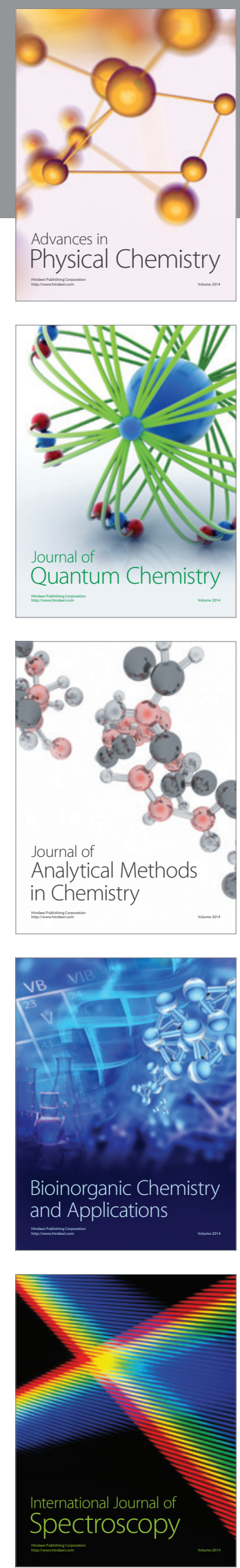